\title{
Amyotrophic Lateral Sclerosis: the Current World Situation

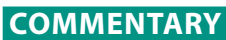

\section{Abstract}

Amyotrophic lateral sclerosis (ALS) is a neurodegenerative disease of unknown cause that affects mainly the motor neurons of the spinal cord, brain stem and brain. The pathogenesis is still obscure and the diagnosis is based on patient history and clinical examination. A handful of factors have been proposed to be associated with ALS; however, the only established risk factors to date are older age, male sex, and a family history of ALS. The familial cases have their historical importance in causative gene identification since through these discoveries much has been uncovered about ALS pathogenesis. The understanding of clinical and epidemiological factors associated with functional impairment is of fundamental for early adoption of measures to promote a better survival and a better quality of life. Rapid diagnosis of amyotrophic lateral sclerosis (ALS) and other neurological disorders is vital if future treatments are to be applied at an early disease stage. The current pace of discovery and identification of novel disease mechanisms in ALS is unprecedented. Advances in this area, however, have also introduced challenges in the heterogeneity of diagnostic definitions affecting this patient population.

\section{Keywords}

Amyotrophic Lateral Sclerosis; Neurodegenerative Disease.

\section{Antonio Gilvan Teixeira} Júnior ${ }^{1,2}$,

Daiane de Lima da Silva, Kaike Santos de Oliveira1, Eron Gurgel Moreira1, Fábia Maria de Santana ${ }^{4}$, Danielly Michele Gondim Matias ${ }^{4}$,

Aurélio Dias Santos 5 , Auricélia Dias Santos ${ }^{6}$, Modesto Leite Rolim-Neto 1,3

1 Faculty of Medicine. Federal University of Cariri, UFCA, Barbalha, Ceara, Brazil.

2 Science without Borders fellow at University of Liverpool, Liverpool, United Kingdom.

3 Faculty of Medicine, Estacio, Juazeiro do Norte, Ceara, Brazil.

4 Postgraduate Program in health Science, Faculty of Medicine - FMABC, Santo André, SP, Brazil.

5 Physiotherapy Course, Faculty Leao Sampaio, Juazeiro do Norte, Ceará, Brazil.

6 Physiotherapist of the Rehabilitation Institute Holistic-FisioNamastê, Juazeiro do Norte, Ceará, Brazil.

\section{Contact information:}

\section{Antonio Gilvan Teixeira Júnior.}

Đ jrir006@hotmail.com
Motor neuron disease (MND) is a collective term for a devastating group of disorders that result in muscle paralysis through the degeneration of motor neurons. Amyotrophic lateral sclerosis (ALS) is the most common form of MND, in which affected individuals generally die from respiratory failure within 2-5 years of diagnosis. [1, 2] Also known as Charcot's disease (France) or Lou Gehrig's disease (USA) is a acquired disease and neurodegenerative of unknown cause that affects mainly the motor neurons of the spinal cord, brain stem and brain. [3] 
ALS is a devastating neurodegenerative disease, and luckily, very rare: only one to two people out of 100,000 develop ALS yearly. This fact, however, makes studies of ALS very challenging since it is very difficult to collect the representative set of clinical samples and this may take up to several years. The pathogenesis is still obscure and the diagnosis is based on patient history and clinical examination. The mechanism of disease onset in humans is not yet fully understood and no effective treatment is available at present. Several pathogenic mechanisms have been proposed to be involved in the loss of the motor neurons in ALS, including oxidative stress, excitotoxicity, protein aggregation, and mitochondrial dysfunction (Figure 1) [4, 5, 6]. Many efforts have been made to find biomarkers to enable earlier diagnosis, to monitor disease progression and to predict prognosis. [6] (Figure 1)
This disease has a global occurrence, with 120,000 new cases per year. The survival rate is on average of 3-5 years, the prognosis is worse in cases where the onset is characterized by bulbar involvement, followed by the cases where signs of involvement of the upper motor neuron (UMN) or lower motor neuron (LMN) first appear in the upper limbs (UL). Survival may be slightly higher in younger individuals and those in which the signs of ALS begin in the lower limbs (LL). $[3,7,8,9,10,11,12,13$, 14] The understanding of clinical and epidemiological factors associated with functional impairment is of fundamental importance for early adoption of measures to promote a better survival and a better quality of life. [14]

It is believed that the incidence of Amyotrophic Lateral Sclerosis (ALS) is the same all over the world, however, there is not a well conducted and com-

Figure 1: Vulnerability factors and mechanism of injury in Motor Neuron Disease. This picture was extracted from Brockington A, Shaw P. (2003). [55, 56, 57]. This legend was modified.

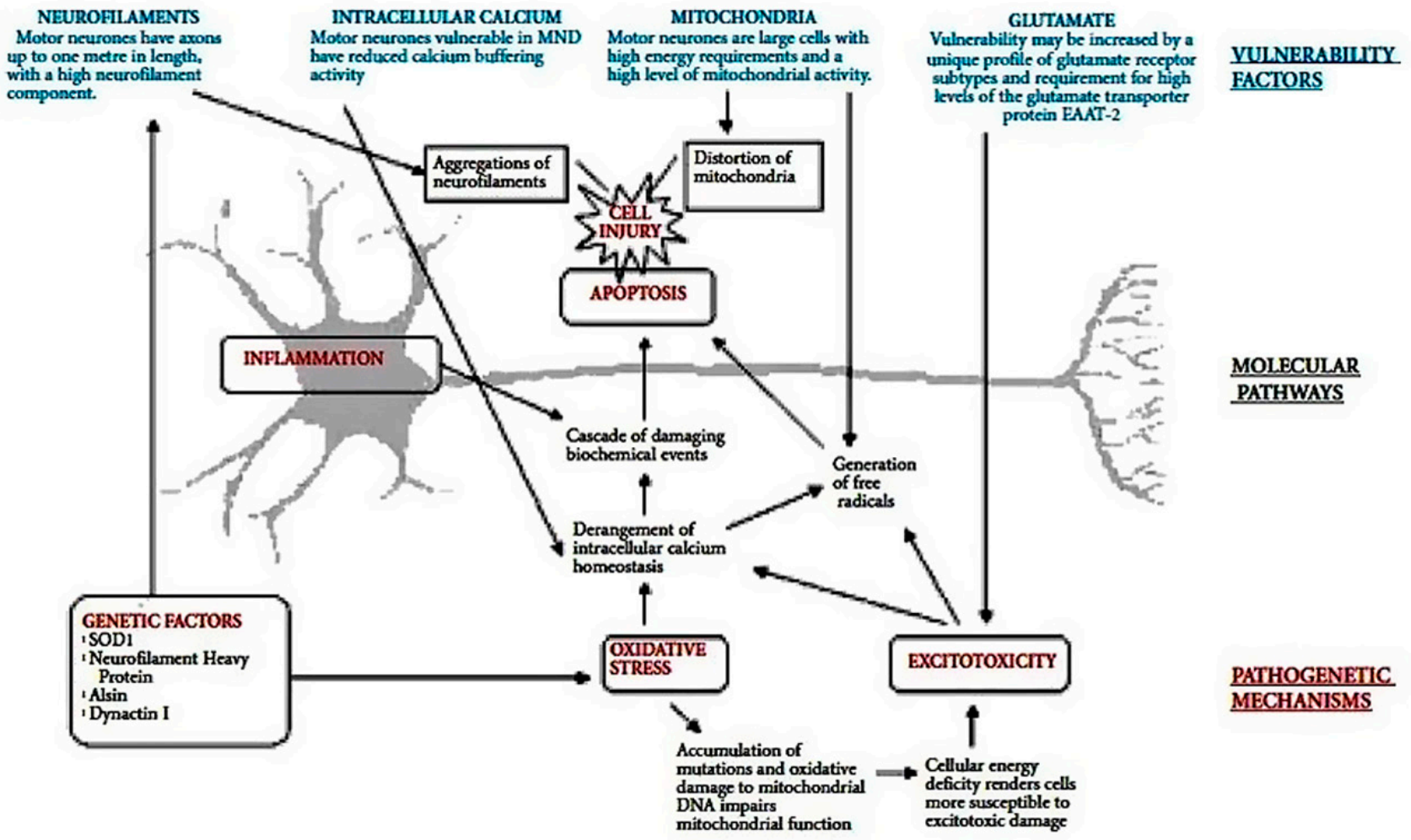


Figure 2: Countries and regions with studies about Amyotrophic Lateral Sclerosis. This picture was adapted from Pereira, RDB (2006). [8].

\begin{tabular}{|c|c|c|c|}
\hline Regions & $\begin{array}{c}\text { Incidence } \\
\text { (per } 100,000 \text { population) }\end{array}$ & $\begin{array}{c}\text { Prevalence } \\
\text { (per 100,000 population) }\end{array}$ & $\begin{array}{c}\text { Publication } \\
\text { Year }\end{array}$ \\
\hline Guam & 3,9 & & 2004 \\
\hline Libya & 3,4 & & 2005 \\
\hline Australia & 2,9 & & 2005 \\
\hline Ireland & 2,8 & 4,7 & 1999 \\
\hline Japan* & 2,5 & 11,31 - Wakayama & 2005 \\
\hline Finland & 2,4 & & 2006 \\
\hline USA & 2,0 & $3-8$ & 2004 \\
\hline Canada* & 2,0 & 6,7 & 2005 \\
\hline Estonia & 1,9 & & 2006 \\
\hline Norway & 1,9 & & 2005 \\
\hline England & 1,7 & & 2001 \\
\hline Italy & 1,7 & 4,03 & 2005 \\
\hline Brazil & 1,5 & & 1998 \\
\hline France* & 1,5 & & 2000 \\
\hline Greece & 1,3 & & 2005 \\
\hline Poland & 0,8 & & 2005 \\
\hline Chile & 0,5 & & 2005 \\
\hline Mexico & 0,4 & & 2005 \\
\hline China & 0,3 & & 2006 \\
\hline
\end{tabular}

parative study among different populations with ALS, among ethnic or geographical area defined outside of Europe and North America (Figure 2). However, research shows that there are individual variations. SLA usually affects more men than women, although more recent studies show that both sexes are affected similarly. Reports of the increase in the ALS cases number in women may be related to the better population identification with previous studies, to the recent effects of a not identified environmental exposure, and/or to the lifestyle changes causing on them a higher exposition to the potential toxics, associated historically with men (smoking, occupational exposures). Other risk factors draw attention and specially to whom may be related to the ALS development, such as exposure to severe electrical shock, strenuous physical activity, soldiers who served in the first Gulf War and professional soccer players. [8] (Figure 2)

The classic disease form is insidious, characterized by asymmetric muscle weakness, limbs and tongue atrophy, in addition to fasciculations and hyperreflexia. Progressively, the reduced muscle strength becomes systemic culminating in quadriplegia. [7, $14,15,16,17]$ The bulbar symptoms usually arise in a disease later stage, being characterized by dysphonia, dysarthria, dysphagia, weakness, atrophy and language fasciculation and later by respiratory failure, the most serious disease symptom and the major cause of death. [7, 14, 15, 18]

The Clinical ALS types are: 1. sporadic; 2. Familiar; 3. ALS plus syndrome; 4. ALS mimicking syndrome; 5. Syndrome with uncertain significance laboratory abnormalities. The diagnostic criteria used for ALS were currently established by the El Escorial World Federation of Neurology, revised in 1998. There is also a sub-classification of the diagnostic criteria El Escorial which subdivides ALS in: defined ALS (typical), probable ALS, possible ALS, suspected ALS. [3]

There are well-established criteria for patients in whom the manifestations are restricted to dysfunction solely of the upper motor neuron (primary lateral sclerosis), lower motor neuron [progressive muscular atrophy (PMA), or bulbar segment (progressive bulbar palsy). [19-23, 24] There are, however, no established criteria for a significant number of patients who present and progress with predominantly upper and only subtle lower motor pathology, or, conversely, predominantly lower motor with only subtle upper motor neuron signs. These patient groups can be further prognostically dichotomized based on the presence or absence of either bulbar or respiratory dysfunction at the time of symptom onset, thus expanding the heterogeneous nature of the disease. [19, 24, 25, 26] This variability in clinical manifestation at the time of initial assessment may be associated with significant variability in survivorship. Superimposed on this clinical variability is the presence or absence of a syndrome of frontotemporal dysfunction that may coexist with many of the motor neuron disorders and, for several, be of prognostic importance. [24, 25] Formal diagnostic criteria for ALS/MND have been developed and modified several times. [24, 27-34] In the absence of widespread acceptance of diagnostic criteria for 
specific disease subtypes, there have been a number of clinical phenotypes described. [23, 24, 35-40]

The multisystem involvement of patients affected by ALS/MND, as well as the varied mechanisms attributed to the disease has led to a multitude of clinical and biological markers proposed as indices of disease progression and/or severity (Figures 1, 3). [24, 40-43] Despite this, one of the primary challenges in studying ALS/MND is the absence of an accepted marker with both the appropriate sensitivity and specificity applicable to the wide range of affected patients. The result of this void in our understanding is a lack of confidence that we can reliably measure disease progression or therapeutic efficacy in our clinical trials. [24]

Also, the potential for genetic markers as correlates of disease subtype and progression has generated much enthusiasm and promise, although remains incompletely understood. There are currently very few established relationships between a specific genetic mutation and a specific pheno- type. The hope is that a potential etiology, at least for a specific phenotype, will emerge and highlight a primary disease mechanism. [24, 44, 45, 46, 47]

Rapid diagnosis of amyotrophic lateral sclerosis (ALS) and other neurologic disorders is vital if future treatments are to be applied at an early disease stage. For genetic causes of these diseases, the current technology lies with sequential Sanger sequencing. However, with an array of multiple genes causing each disease and, additionally, numerous alterations within each gene being potentially harmful, it can be time consuming and costly to diagnose a patient suspected of harboring a detrimental genetic variation (Figure 3). Furthermore, the range of genetic tests at each institution can be limited. It is now plausible that next-generation sequencing (NGS) technologies will eliminate many of these issues. To test this possibility, we have developed a single comprehensive assay containing 25 genes which have, to varying degrees, been implicated in ALS. NGS technology shows promise for the diag-

Figure 3: Genes currently known as associated with ALS classified by common molecular pathways involved in the disease pathophysiology. This picture was extracted from Coatti GC et al. (2015). 50,58,59 This legend was modified.

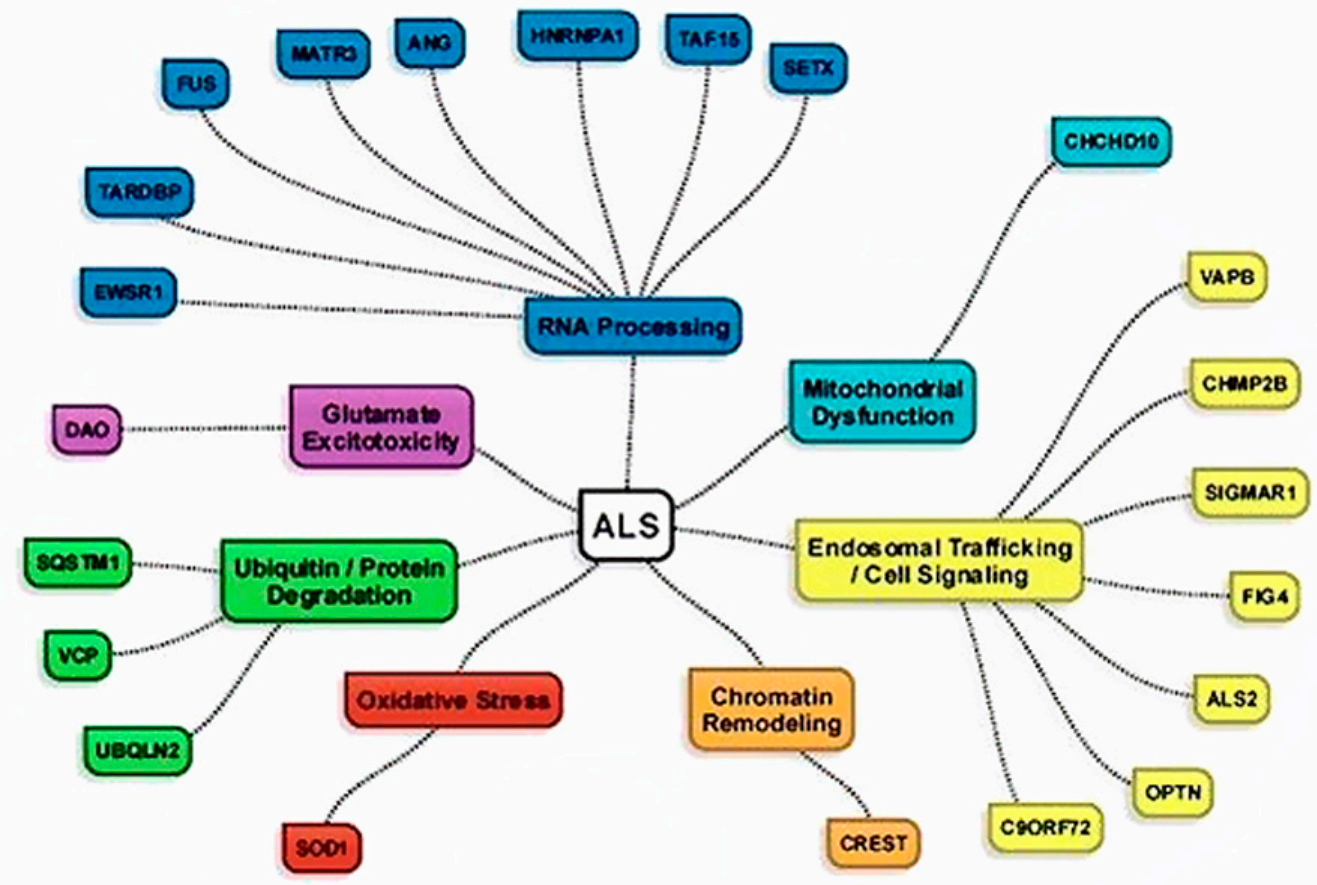


nosis of both familial and sporadic ALS; our rapid high-throughput method is suitable for large scale genetic studies. [48]

A handful of factors have been proposed to be associated with ALS; however, the only established risk factors to date are older age, male sex, and a family history of ALS. [49] Identification of risk factors, especially non-genetic factors, for ALS has proven difficult, and likely reflects the complexity of the disease. Over the last two decades, a great deal of new knowledge has been gathered on ALS, especially in terms of its underlying genetics and potential mechanisms implied by these genetic findings. In contrast, there is substantial impact of non-genetic factors on the etiology of ALS, so far little progress has been made in identifying these factors with some degree of certainty. An improved knowledge of non-genetic risk factors for ALS, hand-in-hand with our increasing knowledge of ALS genetics, should prove more fruitful in deciphering the causes of this devastating disease and eventually providing a cure. [49] (Figure 3)

ALS is mainly classified into two groups: FALS (Familial ALS), for the inherited forms of the disease, and SALS for the sporadic cases, in which there are no affected relatives and where in the majority of cases it is not possible to identify a single causative agent. The familial cases have their historical importance in causative gene identification since through these discoveries much has been uncovered about ALS pathogenesis. Around 33 genes or chromosomal regions have been linked to ALS, providing important clues on the pathophysiological mechanisms of the disease (Figures 1, 3). Although, environmental conditions could play an important role for disease development. [50]

In this context, TBK1 have been implicated as an ALS gene, providing insight into disease biology and suggesting possible directions for drug screening programs. Also, evidence has been provided that OPTN plays a broader role in ALS than previously recognized. Both TBK1 and OPTN are involved in au- tophagy, with TBK1 possibly playing a crucial role in autophagosome maturation as well as the clearance of pathological aggregates. [51, 52, 53] These observations highlight a critical role of autophagy and/ or inflammation in disease predisposition. It is also noteworthy that many drugs have been developed that act on TBK1-mediated pathways owing to their role in tumor cell survival $[53,54]$ and can therefore be used to investigate the effects of drug-dependent loss of function of the kinase. Although, a large genetic dataset for ALS has been provided, which suggests other possible ALS genes and provides a substantial collection of pathogenic variants across ALS genes. After removing the expected number of variants to be seen based on the frequencies of rare variants in controls, we identify more than 70 distinct pathogenic mutations across SOD1, OPTN, TARDBP, VCP, SPG11, and TBK1 that can be used in future efforts to functionally characterize the role of these ALS genes. The identification of TBK1 and the expanded role for OPTN as ALS genes reinforce the growing recognition of the central role of autophagy and neuroinflammation in the pathophysiology of ALS. [53]

About $90 \%$ of cases are sporadic while about $10 \%$ are hereditary and are Caused by mutations in the Super Oxide Dismutase 1 (SOD1), TARDBP and FUS genes. $[2,8]$ The gene therapy attempts to ALS have had as major target the defective activity of superoxide dismutase correction. These experiments were made possible after the animal models development. These experiments still require in vivo evidence. This type of therapy for neuromuscular diseases promises great advances in the coming years, however many obstacles remain to be overcome; as the large number of vectors required for effective treatment; the vectors direction exclusively for motor neurons, the continuous expression and not just the transgene transient; the defects correction without toxic side effects and these therapies application for various forms of MND and ALS, not limited to only a few models. [8] 
Previous research has provided extensive evidence of a pivotal role for excitotoxicity in ALS pathophysiology. Investigations indicate that raised central levels of excitotoxic stimuli could be a primary mechanism involved in the degeneration of motor neurons, and therefore indicate that excitotoxicity could account for the selective motor neuron death observed in ALS. Understanding excitotoxic mechanisms of neuronal cell loss and NMJ degeneration is a vital step in the pathway to developing potential new therapeutic interventions for ALS. The data suggest that targeted interventions, directed specifically at the cell body, might be more efficacious in tackling this devastating disease. [1]

Current clinical practice for patients affected by ALS/MND includes a combination of proactive, adjunctive and symptomatic therapies. Outcome data are lacking relative to the number and variety of treatments used regularly in this population. While treatment approaches are likely more consistent today than they were a decade ago, implementation of these often efficacious treatments has introduced another source of variability in comparing groups of patients for clinical trials. Specifically, maintenance of respiratory health, nutritional stability, physical safety, and aids to improve daily function have an impact on quality of life and disease duration. While these benefits have been difficult to measure in controlled studies, multidisciplinary care has become the standard of treatment for this complex multisystem disease. [4]

The current pace of discovery and identification of novel disease mechanisms in ALS/MND is unprecedented. Despite the great expansion in our knowledge base, there remain some fundamental challenges on issues such as disease definition, appropriate biomarkers of disease progression, interpretation of the multitude of genetic mutations associated with disease, and the impact of aggressive symptomatic treatment. Identification of frontotemporal dysfunction in a majority of patients with both familial and sporadic ALS/MND has both added greatly to the potential for a common underlying mechanism between ALS and frontotemporal dysfunction, while at the same time providing an important prognostic determinant. Advances in this area, however, have also introduced challenges in the heterogeneity of diagnostic definitions affecting this patient population. Our ability to design effective clinical trials that will ultimately lead to efficacious therapies will likely depend upon resolution of some of these most basic questions of diagnosis and disease progression. [4]

\section{References}

1. Blizzard CA et al. Identifying the primary site of pathogenesis in amyotrophic lateral sclerosis-vulnerability of lower motor neurons to proximal excitotoxicity. Disease Models \& Mechanisms (2015) 8, 215-224.

2. Bucchia M et al. Therapeutic Development in Amyotrophic Lateral Sclerosis. ClinTher. 2015 Feb 6.pii: S0149-2918(15)00010-7.

3. Palermo, $\mathrm{S}$ et al. Epidemiology of amyotrophic lateral sclerosis Europe/North America/South America/Asia: discrepancies and similarities: systematic review of the literature. Rev. bras. neurol; 45(2): 5-10, abr.-jun. 2009

4. Menzies FM, Ince PG, Shaw PJ. Mitochondrial involvement in amyotrophic lateral sclerosis. Neurochemlnt 2002; 40: 543-51.

5. Shaw PJ. Molecular and cellular pathways of neurodegeneration in motor neurone disease. J NeurolNeurosurg Psychiatry 2005; 76: 1046-57

6. Elf $\mathrm{K}$ et al. Alterations in muscle proteome of patients diagnosed with amyotrophic lateral sclerosis. J Proteomics. 2014 Aug 28; 108: 55-64.

7. Mitchell, J. Douglas; BORASIO, GianDomenico. Amyotrophic lateral sclerosis. Lancet, London, v. 369, n. 9578, p. 2031-2041, 2007.

8. Pereira, RDB. Epidemiologia: ELA no Mundo (Epidemiology: ALS in World). V Simpósio Brasileiro de Doença do Neurônio Motor/Esclerose Lateral Amiotrófica e I Simpósio Verde vida Saúde, 2006, São Paulo. Esclerose Lateral Amiotrófica: sua manifestação no Brasil. São Paulo. Revista Neurociências, São Paulo, v. 14, n. 2, p. 9-13, 2006

9. Wijesekera, Lokesh C; LEIGH. P. Nigel. Amyotrophic Lateral Sclerosis. Orphanet J. Rare Dis., London, v. 4, n. 3, p. 1-22, 2009.

10. Soriani, M. H.; Desnuelle, Claude. Épidémiologie de la SLA. Rev. Neurol., Paris, v. 165, n.8/9, p. 627-640, 2009.

11. Logroscino, G. et al. Descriptive epidemiology of amyotrophic lateral sclerosis: new evidence and unsolved issues. J. Neurol. Neurosurg. Psychiatry, London, v. 79, n. 1, p. 6-11, 2008. 
12. Matias-Guiu J. et al. Descriptive epidemiology of amyotrophic lateral sclerosis. Neurologia, Barcelona, v. 22, n. 6, p. 368-380, 2007.

13. Logroscino, G. et al. Incidence of amyotrophic lateral sclerosis in Europe. J. Neurol. Neurosurg. Psychiatry, London, v. 81, n. 4, p. 385-390, 2010

14. Alves Cosmo CS et al. Clinical aspects of functional capacity determinants in amyotrophic lateral sclerosis. R. Ci. med. biol., Salvador, v.11, n.2, p.134-139, mai./set. 2012

15. Rowland, Lewis P.; SHNEIDER, Neil. A. Amyotrophic lateral sclerosis. N. Engl. J. Med., Boston, v. 344, n. 22, p. 1688-1700, 2001.

16. Walling, Anne D. Amyotrophic lateral sclerosis: Lou Gehrig's disease. Am. Fam. Physician, Kansas, v. 59, n. 6, p. 1489-1499, 1999.

17. Anequini, I.P. et al. Avaliação das atividades da ABRELA: orientações oferecidas, expectativas atingidas? Rev. Neurociências, São Paulo, v. 14, n. 2, p. 57-64, 2006.

18. Cudkowicz, M. Qureshi M, Shefner J. Measures and markers in amyotrophic lateral sclerosis. NeuroRx., Milwaukee, v. 1, n. 1, p. 273-283, 2004.

19. Sabatelli, M., M. Zollino, M. Luigetti, et al., Uncovering amyotrophic lateral sclerosis phenotypes: clinical features and long-term follow-up of upper motor neuron-dominant ALS. Amyotrophic Lateral Sclerosis, 2011. 12(4): p. 278-82.

20. Rosenfeld, J. andM. Swash,What's in a name? Lumping or splitting ALS, PLS, PMA and the other motor neuron diseases. Neurology, 2006. 66(draft).

21. Ravits, J.M. and A.R. La Spada, ALS motor phenotype heterogeneity, focality, and spread: deconstructing motor neuron degeneration. Neurology, 2009. 73(10): p. 805-11.

22. Turner, M.R., J. Scaber, J.A. Goodfellow, et al., The diagnostic pathway and prognosis in bulbar-onset amyotrophic lateral sclerosis. Journal of the Neurological Sciences, 2010. 294(1-2): p. 81-5.

23. Pringle, C.E., A.J. Hudson, D.G. Munoz, et al., Primary lateral sclerosis. Clinical features, neuropathology and diagnostic criteria. Brain, 1992. 115(Pt 2): p. 495-520.

24. Rosenfeld J, Strong MJ. Challenges in the Understanding and Treatment of Amyotrophic Lateral Sclerosis/Motor Neuron Disease. Neurotherapeutics. 2015. Jan.

25. Georgoulopoulou, E., N. Fini, M. Vinceti, et al., The impact of clinical factors, riluzole and therapeutic interventions on ALS survival: a population based study in Modena, Italy. Amyotrophic Lateral sclerosis \&Frontotemporal Degeneration, 2013. 14(5-6): p. 338-45. 33. Katzberg, $H$

26. Tartaglia, M.C., A. Rowe, K. Findlater, et al., Differentiation between primary lateral sclerosis and amyotrophic lateral sclerosis: examination of symptoms and signs at disease onset and during follow-up. Archives of Neurology, 2007. 64(2): p. 232-6.
27. Strong, M.J., The syndromes of frontotemporal dysfunction in amyotrophic lateral sclerosis. Amyotrophic Lateral Sclerosis, 2008. 9(6): p. 323 - 338.

28. Brooks, B.R., R. Mikker, M. Swash, and T. Munsat, El Escorial revisited: Revised criteria for the diagnosis of amyotrophic lateral sclerosis. ALS and Other Motor Neuron Diseases, 2000. 1: p. 293- 99.

29. Traynor, B.J. et al., Clinical features of amyotrophic lateral sclerosis according to the El Escorial and Airlie House diagnostic criteria: A population-based study. Archives of Neurology, 2000. 57(8): p. 1171-1176

30. Boekestein, W.A., B.U. Kleine, G. Hageman, H.J. Schelhaas, and M.J. Zwarts, Sensitivity and specificity of the 'Awaji' electrodiagnostic criteria for amyotrophic lateral sclerosis: retrospective comparison of the Awaji and revised El Escorial criteria for ALS. Amyotrophic Lateral Sclerosis, 2010. 11(6): p. 497-501.

31. Carvalho, M.D. and M. Swash, Awaji diagnostic algorithm increases sensitivity of El Escorial criteria for ALS diagnosis. Amyotrophic Lateral Sclerosis, 2009. 10(1): p. 53-7.

32. Costa, J., M. Swash, and M. de Carvalho, Awaji criteria for the diagnosis of amyotrophic lateral sclerosis: a systematic review. Archives of Neurology, 2012. 69(11): p. 1410-6.

33. Higashihara, M., M. Sonoo, I. Imafuku, et al., Fasciculation potentials in amyotrophic lateral sclerosis and the diagnostic yield of the Awaji algorithm. Muscle \& Nerve, 2012. 45(2): p. 175-82.

34. Strong, M.J., G.M. Grace, M. Freedman, et al., Consensus criteria for the diagnosis of frontotemporal cognitive and behavioural syndromes in amyotrophic lateral sclerosis. [Erratum appears in Amyotroph Lateral Scler. 2009 Aug; 10(4): 252]. Amyotrophic Lateral Sclerosis, 2009. 10(3): p. 131-46.

35. Beghi, E., A. Chio, P. Couratier, et al., The epidemiology andtreatment of ALS: focus on the heterogeneity of the disease andcritical appraisal of therapeutic trials. Amyotrophic Lateral Sclerosis, 2011. 12(1): p. 1-10

36. Swash, M. and J. Desai, Motor neuron disease: Classification and nomenclature. Amyotrophic Lateral Sclerosis, 2000. 1(2): p. $105-112$

37. Swash, M. and J. Desai, Motor neuron disease: classification and nomenclature. Amyotrophic Lateral Sclerosis \& Other Motor Neuron Disorders, 2000. 1(2): p. 105-12.

38. Chio, A., A. Calvo, C. Moglia, et al., Phenotypic heterogeneity of amyotrophic lateral sclerosis: a population based study. Journal of Neurology, Neurosurgery \& Psychiatry, 2011. 82(7): p. 740-6.

39. Hu, M., C. Ellis, A. Al-Chalabi, P. Leigh, and C. Shaw, Flail arm syndrome: a distinctive variant of amyotrophic lateral sclerosis. J NeurolNeurosurg Psychiatry, 1998. 65: p. 950-951.

40. Kobayashi, Z., K. Tsuchiya, T. Arai, et al., Pseudopolyneuritic form of ALS revisited: clinical and pathological heterogeneity. Neuropathology, 2010. 30(4): p. 372-80. 
41. Turner, M.R., R. Bowser, L. Bruijn, et al., Mechanisms, models and biomarkers in amyotrophic lateral sclerosis. Amyotrophic Lateral sclerosis \&Frontotemporal Degeneration, 2013. 14 Suppl 1: p. 19-32.

42. Bede, P., A.L.W. Bokde, S. Byrne, et al., Spinal cord markers in ALS: diagnostic and biomarker considerations. Amyotrophic Lateral Sclerosis, 2012. 13(5): p. 407-15.

43. Bowser, R., M.R. Turner, and J. Shefner, Biomarkers in amyotrophic lateral sclerosis: opportunities and limitations. Nature Reviews Neurology, 2011. 7(11): p. 631-8.

44. Su, X.W., J.R. Broach, J.R. Connor, G.S. Gerhard, and Z. Simmons, Genetic heterogeneity of amyotrophic lateral sclerosis: implications for clinical practice and research. Muscle \& Nerve, 2014. 49(6): p. 786-803.

45. Sabatelli, M., A. Conte, and M. Zollino, Clinical and genetic heterogeneity of amyotrophic lateral sclerosis. Clinical Genetics, 2013. 83(5): p. 408-16

46. Abel, O., J.F. Powell, P.M. Andersen, and A. Al-Chalabi, ALSoD: A user-friendly online bioinformatics tool for amyotrophic lateral sclerosis genetics. Human Mutation, 2012. 33(9): p. 1345-51. Challenges in Understanding and Treatment of ALS/MND

47. Renton, A.E., A. Chio, and B.J. Traynor, State of play in amyotrophic lateral sclerosis genetics. Nature Neuroscience, 2014. 17(1): p. 17-23

48. Morgan $S$ et al. Investigation of next-generation sequencing technologies as a diagnostic tool for amyotrophic lateral sclerosis. Neurobiol Aging. 2015 Mar; 36(3): 1600.e5-8.

49. Ingre $C$ et al. Risk factors for amyotrophic lateral sclerosis. Clinical Epidemiology 2015, Feb; 7: 181-193.

50. Coatti GC et al. Stem cells for amyotrophic lateral sclerosis modeling and therapy: Myth or fact? Cytometry A. 2015 Mar; 87(3): 197-211.

51. M. Pilli, J. Arko-Mensah, M. Ponpuak, E. Roberts, S. Master, M. A. Mandell, N. Dupont, W. Ornatowski, S. Jiang, S. B. Bradfute, J. A. Bruun, T. E. Hansen, T. Johansen, V. Deretic, TBK-1 promotes autophagy-mediated antimicrobial defense by controlling autophagosome maturation. Immunity 37, 223-234 (2012)

52. J. Korac, V. Schaeffer, I. Kovacevic, A. M. Clement, B. Jungblut, C. Behl, J. Terzic, I. Dikic, Ubiquitin-independent function of optineurin in autophagic clearance of/sciencemag.org/content/ early/recent/19 February 2015/Page 6/10.1126/science.aaa3650 protein aggregates. J. Cell Sci. 126, 580-592 (2013).

53. Cirulli ET et al. Exome sequencing in amyotrophic lateral sclerosis identifies risk genes and pathways. Science.2015 Feb 19.

54. J. Li, J. Huang, J. H. Jeong, S. J. Park, R. Wei, J. Peng, Z. Luo, Y. T. Chen, Y. Feng, J. L. Luo, Selective TBK1/IKKi dual inhibitors with anticancer potency. Int. J. Cancer 134, 1972-1980 (2014).
55. Brockington A, Shaw P. Developments in the treatment of Motor Neurone Disease. ACNR, 2003, nov/dez, 3(5): 13-19.

56. Shaw PJ, Eggett CJ. Molecular factors underlying selective vulnerability of motor neurons to neurodegeneration in amyotrophic lateral sclerosis. J Neurol. 2000; 247 Suppl 1: I 17-27

57. Shaw PJ. Mechanisms of cell death and treatment prospects in motor neuron disease. Hong Kong Med J. 2001; 7: 267-280

58. Robberecht $W$, Philips $T$. The changing scene of amyotrophic lateral sclerosis. Nat Rev Neurosci 2013; 14: 248-264.

59. Ferraiuolo L, Kirby J, Grierson AJ, Sendtner M, Shaw PJ. Molecular pathways of motor neuron injury in amyotrophic lateral sclerosis. Nat RevNeurol2011; 7: 616-630.

\section{Comment on this article:}
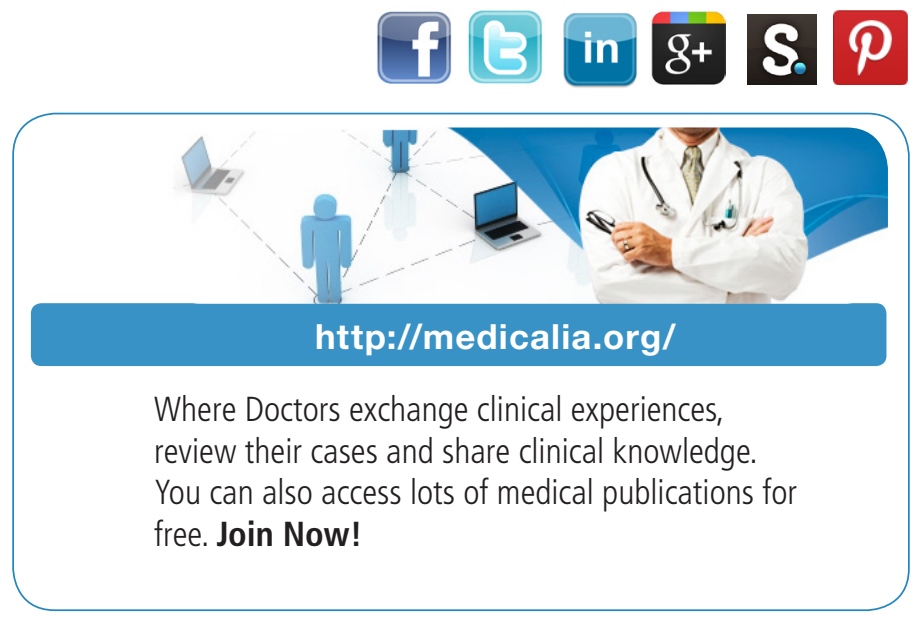

\section{Publish with iMedPub}

\section{http://www.imed.pub}

International Archives of Medicine is an open access journal publishing articles encompassing all aspects of medical science and clinical practice. IAM is considered a megajournal with independent sections on all areas of medicine. IAM is a really international journal with authors and board members from all around the world. The journal is widely indexed and classified Q1 in category Medicine. 